\title{
MEK/ERK pathway mediates UVB-induced AQP1 downregulation and water permeability impairment in human retinal pigment epithelial cells
}

\author{
QIN JIANG $^{1 *}$, CONG CAO $^{2 *}$, SHAN LU $^{3}$, REBECCA KIVLIN ${ }^{3}$, BRITTANY WALLIN $^{3}$, \\ WENMING $\mathrm{CHU}^{2}, \mathrm{ZHIGANG} \mathrm{BI}^{1}, \mathrm{XINRU} \mathrm{WANG}^{1}$ and YINSHENG WAN ${ }^{3}$ \\ ${ }^{1}$ Eye Hospital, Nanjing Medical University, Nanjing 210029, P.R. China; ${ }^{2}$ Department of \\ Molecular Microbiology and Immunology, Brown University, Providence, RI 02903; \\ ${ }^{3}$ Department of Biology, Providence College, Providence, RI 02918, USA
}

Received December 20, 2008; Accepted February 23, 2009

DOI: 10.3892/ijmm_00000191

\begin{abstract}
Aquaporins (AQPs) are a family of 13 small $(\sim 30 \mathrm{kDa} /$ monomer), hydrophobic, integral membrane proteins. AQPs are expressed in various epithelial and endothelial cells involved in fluid transport. Here, we demonstrated for the first time that AQP1 is expressed in cultured human retinal pigment epithelial (RPE) cells (ARPE-19 cell line). Ultraviolet radiation (UVB) and $\mathrm{H}_{2} \mathrm{O}_{2}$, two major factors causing RPE cell damage, induced AQP1 downregulation which was mediated by MEK/ERK activation. UV and $\mathrm{H}_{2} \mathrm{O}_{2}$ as well as AQP1-specific siRNA knockdown impaired water permeability of ARPE-19 cells. Notably, pretreatment with all-trans retinoic acid attenuated UV- and $\mathrm{H}_{2} \mathrm{O}_{2}$-induced AQP1 downregulation and water permeability impairment. Considering that water permeability is involved in multiple functions of RPE cells such as cellular junction formation, fluid or protein exchange and barrier formation, our data elucidated a novel mechanism through which UV radiation and oxidative stress induce eye cell damage. Our results further support the notion that all-trans retinoic acid might be useful for protection against UV or oxidative stress-induced eye cell damage.
\end{abstract}

Correspondence to: Dr Qin Jiang, Eye Hospital, Nanjing Medical University, Nanjing 210029, P.R. China

E-mail: jqin710@vip.sina.com

Dr Yinsheng Wan, Department of Biology, Providence College, 549 River Avenue, Providence, RI 02918-0001, USA

E-mail: yswan@providence.edu

*Contributed equally

Key words: UV radiation, aquaporin 1, retinal pigment epithelial cells, water permeability

\section{Introduction}

The role of UV in skin carcinogenesis has been extensively studied because of the large exposure of this organ. The eye is another directly exposed organ; however, very little is known about the effect of UV exposure on the retina (1). One previous study described the in vitro effect of UV-C irradiation on lens $\alpha$-crystallin, a protein thought to play a role in maintaining lens transparency (2), whereas other studies have analyzed signaling pathways associated with corneal epithelial cell and retinal pigment epithelial cell apoptosis $(1,2)$. Components of UV are capable of reaching the human retina, as shown by a structural study of the rat retina exposed to UV. Both UV-B and UV-C produce alterations which affect the function of the retina (3). However, the detailed mechanisms involved in UV-induced eye damage have not been fully studied.

Retinal pigment epithelial (RPE) cells are highly polarized cells. Their integrity is critical for the maintenance of neural retina functions. In healthy subjects, RPE cells have a limited potential of proliferation associated with growth and age, while in uncontrolled RPE cells proliferation may contribute to retinal diseases such as proliferative vitreoretinopathy (PVR) $(4,5)$. On the other hand, RPE is thought to be the prime early target for age-related macular degeneration (AMD), which involves RPE cell death and atrophy of the photoreceptors (6). Furthermore, RPE cells are also major targets for UV radiation or oxidative stress-induced damage $(1,7,8)$, which is also a major cause of AMD (6). Studies performed in RPE fields used a spontaneously arising human RPE cell line, or ARPE-19, as a cellular model $(1,9)$. ARPE-19 cells exhibit a polarization, capable of tight junction formation (9).

Aquaporins (AQPs) are a family of small $(\sim 30 \mathrm{kDa} /$ monomer), hydrophobic, integral membrane proteins which are expressed widely in the animal and plant kingdoms, with 13 members having thus far been identified in mammals $(10,11)$. AQPs are expressed in various epithelia and endothelia involved in fluid transport, as well as in cell types that were originally thought not to carry out fluid transport (11). $\mathrm{AQP1}$ is thus far the only AQP that is expressed in RPE 
$(12,13)$. AQP1 mediates osmolarity-driven water transport across epithelial cells linking the proximal tubules and descending thin limbs of Henle's loop, and across endothelial cells of the descending vasa recta (9). Studies in AQP1-null mice have demonstrated that AQP1 mediates osmolaritydriven water transport across the epithelial barrier in serosal membranes such as the pleura and the peritoneum, in lung microvessels, and in the cornea (14). AQP1 in RPE in vivo probably contributes to the efficient trans-epithelial water transport across RPE, maintains retinal attachment, and prevents subretinal edema (1).

Given that UV radiation and oxidative stress are major causes of RPE cell damage and that AQP1 plays an important role in maintaining the normal function of RPE (13), we conducted this study to test the effects of UV and oxidative stress on AQP1 expression and function. We demonstrated for the first time that $\mathrm{UV}$ radiation and $\mathrm{H}_{2} \mathrm{O}_{2}$ treatment downregulates AQP1 expression in ARPE-19 cells. We found that ROS-mediated MEK/ERK activation is involved in this downregulation process. AQP1-mediated water permeability is also impaired by UV and $\mathrm{H}_{2} \mathrm{O}_{2}$ treatment. Notably, all-trans retinoic acid (atRA) pre-treatment attenuated UV- and $\mathrm{H}_{2} \mathrm{O}_{2}$ induced AQP1 downregulation and water permeability impairment. Since water permeability is involved in multiple functions of RPE cells such as cellular junction formation, fluid or protein exchange and barrier formation $(13,15-17)$, our study elucidated a novel mechanism through which UV radiation and oxidative stress induce eye cell damage. Our data also support the notion that all-trans retinoic acid might be useful for protection against UV- or oxidative stress-induced eye cell damage.

\section{Materials and methods}

UV light apparatus. The UV-irradiation apparatus used in this study was previously described (18-21). Before UV irradiation, cells were washed with $1 \mathrm{ml}$ pre-warmed PBS buffer. Cells were irradiated at the desired intensity without a plastic dish lid. After UV irradiation, cells were returned for incubation in basal medium with treatments for indicated time periods.

Chemicals and reagents. Rabbit anti-human aquaporin 1 (AQP1) was obtained from Chemicon (Temecula, CA) (AB3065), and anti-p-MEK, anti-MEK, anti-p-ERK, antiERK were obtained from Cell Signaling Technology (Danvers, MA). Monoclonal mouse anti- $\beta$-actin, all-trans retinoic acid (atRA) and n-acetyl-1-cysteine (NAC) were obtained from Sigma (St. Louis, MO). U0126, PD98059, JNKi and SB203580 were from CalbioChem (San Diego, CA).

Cell culture. Human retinal pigment epithelial (RPE) cells (ARPE-19 cell line) were a gift from the laboratory of Dr Fu Shang (22). ARPE-19 cells were maintained in a DMEM medium supplemented with $10 \%$ fetal bovine serum, penicillin/streptomycin and $4 \mathrm{mM}$ L-glutamine, in a $\mathrm{CO}_{2}$ incubator at $37^{\circ} \mathrm{C}$.

Western blot analysis. As reported previously (19,20,23), $20 \mu \mathrm{g}$ protein from cells with different treatments was separated by SDS-PAGE and transferred onto PVDF membranes
(Millipore, Bedford, MA). After blocking, membranes were incubated with specific antibodies. Antibody binding was detected using an enhanced chemiluminescence (ECL) detection system (GE, Piscataway, NJ) by autoradiography with Hyperfilm.

Measurement of water permeability. The water permeability was measured using a well established method as described previously (20). The coverslips with ARPE-19 cells were mounted in a closed perfusion chamber on the stage of a Zeiss fluorescence microscope. The cells were loaded with calcein, and the water permeability measurement was conducted (see details below). First, the cells were loaded with calcein by a 5-min exposure to $20 \mu \mathrm{M}$ calcein-acetoxymethyl ester (calcein-AM, Invitrogen, Carlsbad, CA) in 300 mosM PBS. The loading of the cells with calcein was performed at $30^{\circ} \mathrm{C}$ for $10 \mathrm{~min}$. The subsequent water permeability measurements were carried out at $10^{\circ} \mathrm{C}$ to decrease the water diffusion through the lipid bilayer of the plasma membrane. The cells were then perfused with cold 300 mosM PBS for 5 min, then, the perfusate was switched to 150 mosM PBS at the same temperature. Fluorescence intensity of perfused cells was recorded every 2 min $(0,2,4$ and $6 \mathrm{~min})$ with excitation at $488 \mathrm{~nm}$ and emission at 515-525 $\mathrm{nm}$ (green) before and after the solution switch. The series of images were analyzed by measuring the time course of the calcein fluorescence in cytoplasmic regions of individual cells, and the fluorescence intensity was quantified. The half life of deduction of fluorescence intensity was used as a comparable indicator of water permeability. At least 100 cells in 6 random views were quantified for relative fluorescence intensity.

Reactive oxygen species (ROS) detection. ROS generation was detected by FACS analysis as described previously (20). Briefly, cultured ARPE-19 cells were loaded with $1 \mu \mathrm{M}$ of fluorescent dye dihydrorhodamine (DHR) $2 \mathrm{~h}$ before treatment, which reacts with ROS in cells and results in a change of fluorescence. After being treated with UV with or without reagents for the desired time, ARPE-19 cells were trypsinized, suspended in ice-cold PBS and fixed in $70 \%$ ethyl alcohol at $-20^{\circ} \mathrm{C}$. Changes in fluorescence in the drug-treated cells were quantified by FACS analysis. Induction of ROS generation was expressed in arbitrary units.

RNA interference (RNAi) experiments. Custom SMART pool ${ }^{\circledR}$ RNAi duplexes for AQP1 were from Dharmacon Research (Lafayette, CO). As described previously (24), ARPE-19 cells were cultured in complete medium for 4 days. Cells $\left(50 \times 10^{4}\right)$ were seeded into a 6 -well plate 1 day prior to transfection and cultured to $60-70 \%$ confluence the following day. Lipofectamine ${ }^{\mathrm{TM}} \operatorname{LTX}(6.25 \mu 1)$ together with $2.5 \mu 1$ PLUS $^{\text {TM }}$ Reagent (Invitrogen, Indianapolis, IN) was diluted in $90 \mu 1$ of DMEM for $5 \mathrm{~min}$ in room temperature. Then, $8 \mu \mathrm{l}$ AQP1 siRNA was mixed with DMEM containing Lipofectamine together with PLUS reagent and incubated for $30 \mathrm{~min}$ at room temperature. Finally, the complex was added to the well containing $2 \mathrm{ml}$ medium with the final AQP1 siRNA concentration of $100 \mathrm{nM}$. AQP1 protein expression was determined by Western blot analysis $48 \mathrm{~h}$ after transfection. 
A

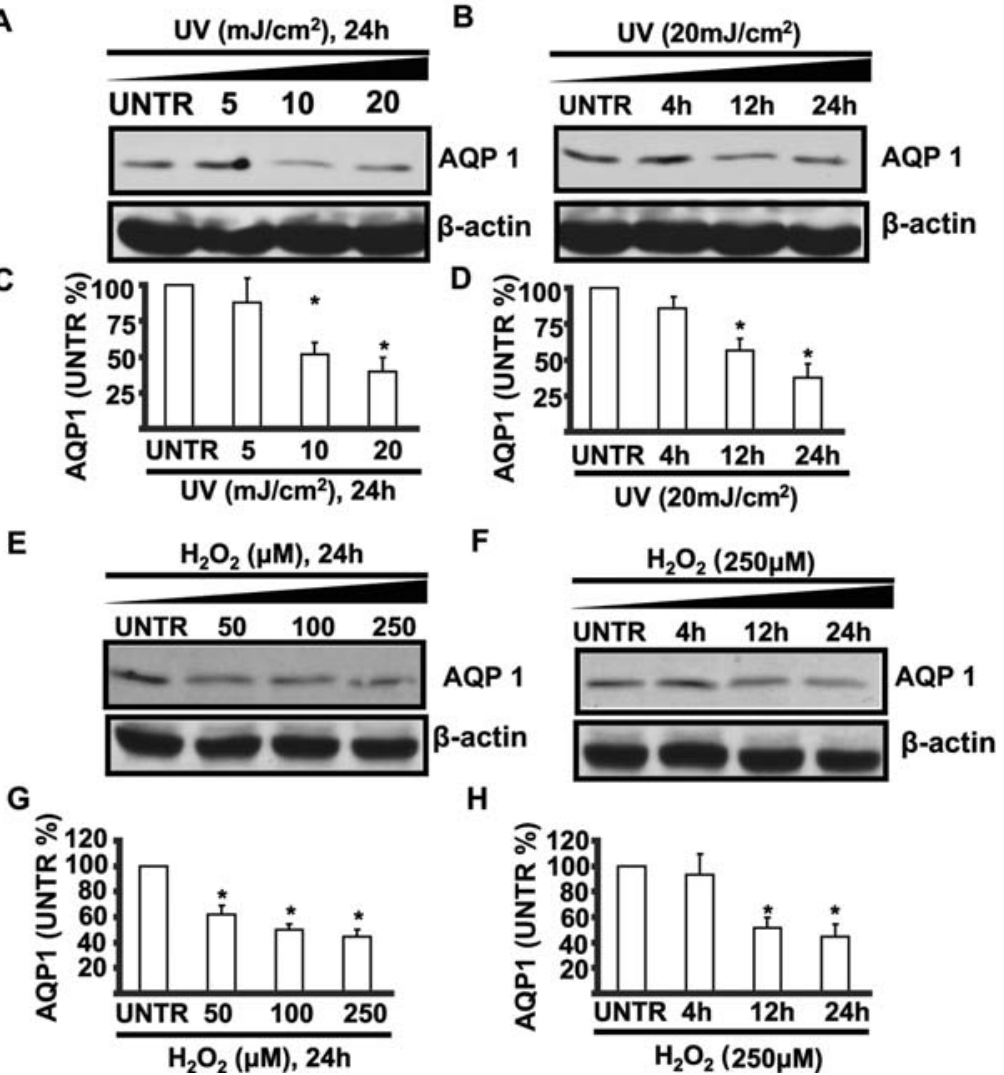

Figure 1. UV and $\mathrm{H}_{2} \mathrm{O}_{2}$ induce AQP1 downregulation in cultured human retinal pigment epithelial ARPE-19 cells. Cells were treated with UV (5, 10 and $\left.20 \mathrm{~mJ} / \mathrm{cm}^{2}\right)$, or $\mathrm{H}_{2} \mathrm{O}_{2}(50,100,250 \mu \mathrm{M})$ and harvested at $24 \mathrm{~h}$ as shown in A and C, E and G (respectively), or treated with UV $\left(20 \mathrm{~mJ} / \mathrm{cm}^{2}\right)$ and harvested at 4,12 and $24 \mathrm{~h}$ or $\mathrm{H}_{2} \mathrm{O}_{2}(250 \mu \mathrm{M})$ and harvested at 4, 12, $24 \mathrm{~h}$ as shown in B and D, F and $\mathrm{H}$ (respectively). AQP1 was analyzed by Western blot analysis. Data represent the mean $\pm \mathrm{SE}$ of three independent experiments. ${ }^{*} \mathrm{P}<0.05$ compared with the untreated (UNTR) group (lane 1).

Statistical analysis. The values in the figures were expressed as the means \pm standard error (SE). The figures in this study are representative of more than 3 different experiments. Statistical analysis of the data between the control and treated groups was performed by the Student's t-test. Values $\mathrm{p}<0.05$ were considered statistically significant.

\section{Results}

$U V$ and $\mathrm{H}_{2} \mathrm{O}_{2}$ downregulate AQP1 expression in cultured human retinal pigment epithelial ARPE-19 cells. We studied whether UV and $\mathrm{H}_{2} \mathrm{O}_{2}$ affected AQP1 expression in cultured ARPE-19 cells. As shown in Fig. 1A and C, UV induced AQP1 downregulation in a dose-dependent manner, and AQP1 started to decrease at $10 \mathrm{~mJ} / \mathrm{cm}^{2}$ of UV and was most obvious at $20 \mathrm{~mJ} / \mathrm{cm}^{2}$ of UV. UV also induced AQP1 downregulation in a time-dependent manner. AQP1 started to decrease at $12 \mathrm{~h}$ and was most obvious at $24 \mathrm{~h}$ after $20 \mathrm{~mJ} /$ $\mathrm{cm}^{2}$ of UV radiation (Fig. $1 \mathrm{~B}$ and D). Similar results were also noted in $\mathrm{H}_{2} \mathrm{O}_{2}$-treated ARPE-19 cells (Fig. 1E-H). Collectively, our data demonstrated that UV and ROS induced AQP1 downregulation in cultured human retinal pigment epithelial ARPE-19 cells.

$M E K / E R K$ inhibitors and antioxidants inhibit $U V$ - and $\mathrm{H}_{2} \mathrm{O}_{2}^{-}$ induced AQP1 downregulation in cultured human retinal pigment epithelial ARPE-19 cells. We studied the signal pathways involved in this UV-induced AQP1 downregulation. Cultured ARPE-19 cells were pretreated with JNKi (JNK inhibitor), SB202580 (a p38 kinase inhibitor), PD98059 and U0126 (MEK/ERK inhibitors) followed by UV radiation. The results showed that MEK/ERK inhibitors PD98059 and U0126 inhibited UV-induced AQP1 downregulation, while the other inhibitors had little effect (Fig. 2A and B). Furthermore, PD98059 and U0126 also inhibited $\mathrm{H}_{2} \mathrm{O}_{2}$-induced AQP1 downregulation (Fig. 2C and D). Since ROS production plays critical roles in UV-induced cellular responses (25), we next tested the role of antioxidants in UVand $\mathrm{H}_{2} \mathrm{O}_{2}$-induced AQP1 downregulation. We found that pretreatment with $\mathrm{N}$-acetyl cysteine (NAC) largely inhibited UVand $\mathrm{H}_{2} \mathrm{O}_{2}$-induced AQP1 downregulation (Fig. 2E and F). As expected, NAC pretreatment inhibited UV- and $\mathrm{H}_{2} \mathrm{O}_{2}$-induced ROS production (Fig. 2G). Furthermore, NAC also inhibited UV-induced ERK activation (Fig. 2H and I), which suggests that ROS-mediated MEK/ERK activation is involved in UVinduced AQP1 downregulation.

All-trans retinoic acid (atRA) attenuates $U V$ - and $\mathrm{H}_{2} \mathrm{O}_{2-}$ induced AQP1 downregulation in cultured human retinal pigment epithelial ARPE-19 cells. Since our previous studies demonstrated that atRA inhibits AQP3 downregulation in cultured skin keratinocytes (19), we next tested the effect of 
A.
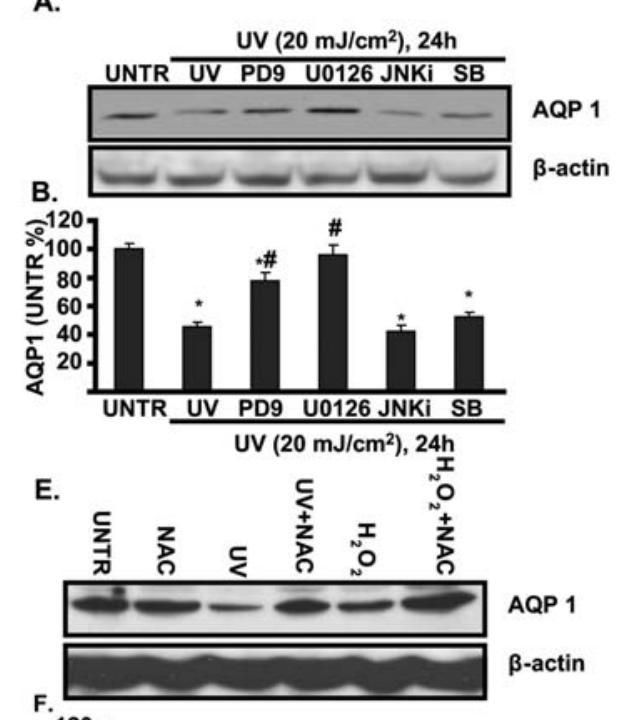

H.

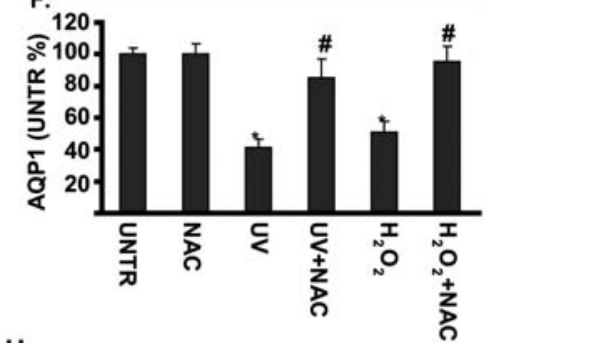

H.

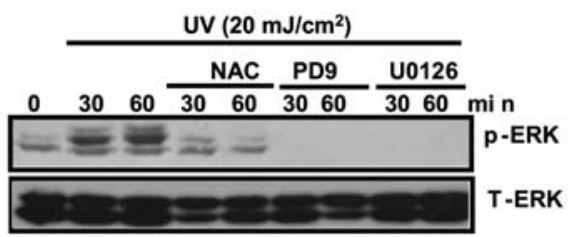

C.

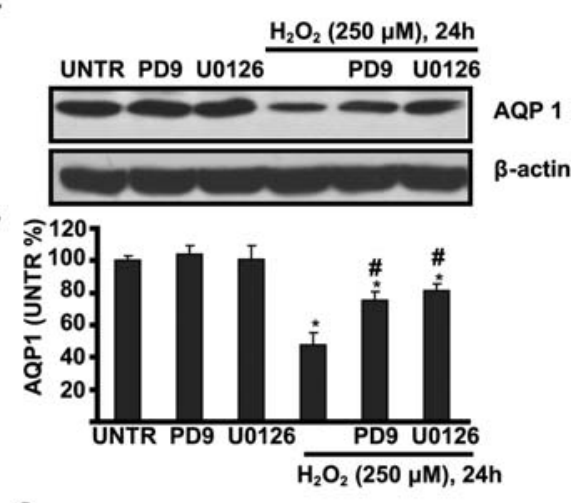

G.

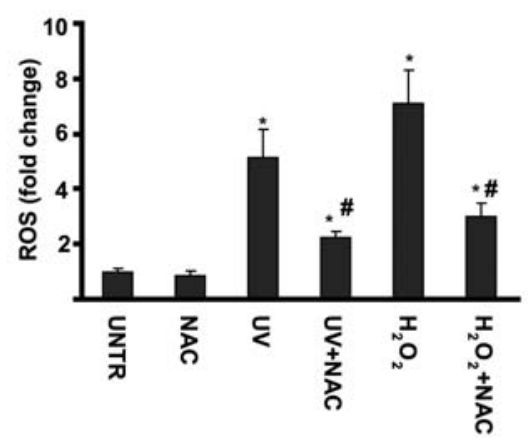

I.

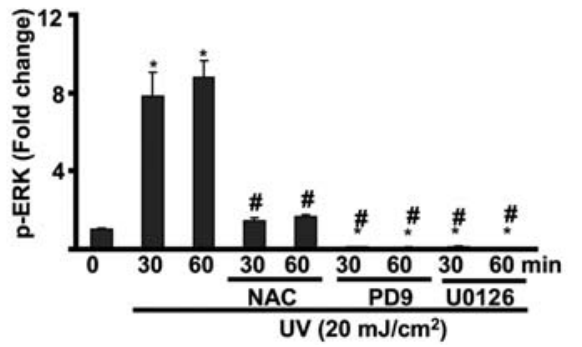

Figure 2. MEK/ERK inhibitors and antioxidant NAC inhibit $\mathrm{UV} / \mathrm{H}_{2} \mathrm{O}_{2}$-induced $\mathrm{AQP} 1$ downregulation. ARPE-19 cells were pretreated with MEK/ERK inhibitor PD98059 (PD9, $1 \mu \mathrm{M}$ ) or U0126 $(1 \mu \mathrm{M})$, JNK inhibitor (JNKi, $1 \mu \mathrm{M})$ and p38 inhibitor SB203580 (SB, $1 \mu \mathrm{M})$ for $1 \mathrm{~h}$, followed by UV (20 mJ/ $\mathrm{cm}^{2}$ ) radiation $(\mathrm{A}$ and $\mathrm{B})$ or treatment with $\mathrm{H}_{2} \mathrm{O}_{2}(\mathrm{C}$ and D), and cells were harvested at $24 \mathrm{~h}$ for AQP1 detection by Western blotting as mentioned above. ARPE-19 cells were pretreated with or without $\mathrm{N}$-acetyl cysteine (NAC, $400 \mu \mathrm{M}$ ) for $1 \mathrm{~h}$, followed by UV radiation $\left(20 \mathrm{~mJ} / \mathrm{cm}^{2}\right)$ or $\mathrm{H}_{2} \mathrm{O}_{2}(250 \mu \mathrm{M})$. AQP1 expression was detected by Western blotting after $24 \mathrm{~h}$ (E and F), and ROS production was detected at $2 \mathrm{~h}(\mathrm{G})$. ERK phosphorylation in cells with indicated treatments was detected by Western blotting $(\mathrm{H}$ and $\mathrm{H})$. Data represent the mean $\pm \mathrm{SE}$ of three independent experiments. * $\mathrm{P}<0.05$ with untreated (UNTR) group (lane 1); ${ }^{\mathrm{P}}<0.05$ with $\mathrm{UV}$ - or $\mathrm{H}_{2} \mathrm{O}_{2}$-treated group.

atRA on UV-induced AQP1 downregulation in cultured ARPE-19 cells. Pre-treatment with atRA for $1 \mathrm{~h}$, dosedependently rescued UV- (Fig. 3A and B) or $\mathrm{H}_{2} \mathrm{O}_{2^{-}}$(Fig. 3C and D) induced AQP1 downregulation. Furthermore, we found that pre-treatment with atRA remarkably reduced UVor $\mathrm{H}_{2} \mathrm{O}_{2}$-induced ERK activation (Fig. 3E). Notably, atRA alone upregulated AQP1 expression in cultured ARPE-19 cells in both a dose- (Fig. 3F and G) and time- (Fig. 3H and I) dependent manner. These results indicate that atRA, which alone induced AQP1 upregulation, attenuated UV- or $\mathrm{H}_{2} \mathrm{O}_{2}$ induced AQP1 downregulation in ARPE-19 cells.

All-trans retinoic acid attenuates $U V$ - and $\mathrm{H}_{2} \mathrm{O}_{2}$-induced impairment of water permeability in cultured human retinal pigment epithelial ARPE-19 cells. We tested the functional results of AQP1 downregulation by focusing on water permeability. First, as shown in Fig. 4A and B, AQP1- specific siRNA successfully knocked down AQP1 expression in ARPE-19 cells. Second, while atRA, which alone upregulated AQP1 expression (as shown in Fig. 3F and $\mathrm{H}$ ), enhanced water permeability, UV radiation and $\mathrm{H}_{2} \mathrm{O}_{2}$ treatment as well as AQP1 siRNA knockdown impaired water permeability in ARPE-19 cells (Fig. 4C and D). Furthermore, pre-treatment with atRA attenuated UV- (Fig. 4E) and $\mathrm{H}_{2} \mathrm{O}_{2}$ - (Fig. 4F) induced decrease of water permeability.

\section{Discussion}

We demonstrated for the first time that AQP1 is functionally expressed in cultured human retinal pigment epithelial cell line ARPE-19, which provides a cellular model by which to examine the function of AQP1 in RPE. We found that UV radiation and $\mathrm{H}_{2} \mathrm{O}_{2}$ treatment downregulated AQP1 expression (Fig. 1) and impaired water permeability (Fig. 4) in cultured 
A.

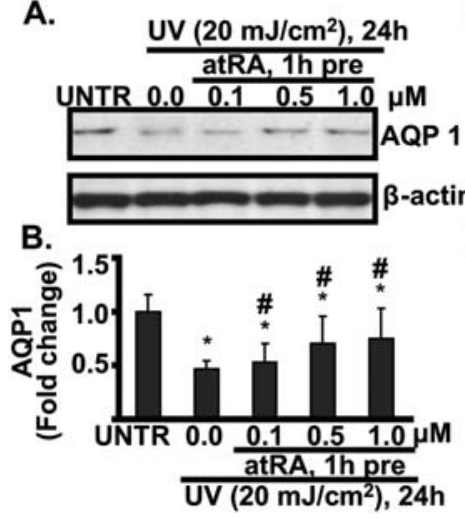

E.
C.

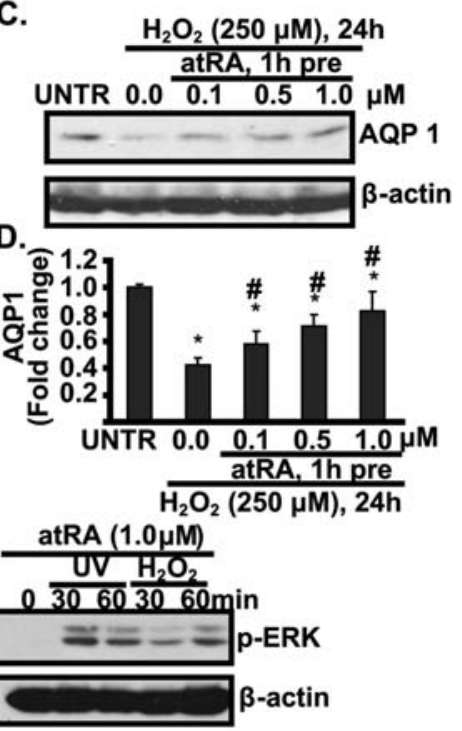

H.

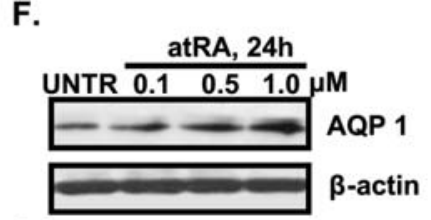

G.

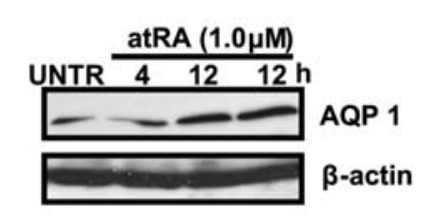

I.

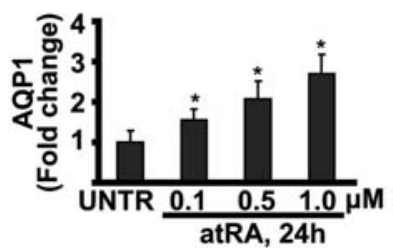

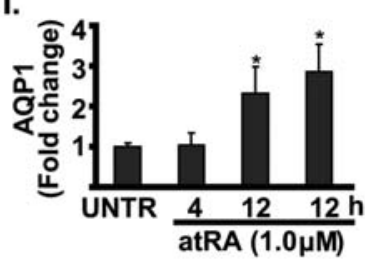

Figure 3. All-trans retinoic acid (atRA) attenuates UV- and $\mathrm{H}_{2} \mathrm{O}_{2}$-induced AQP1 downregulation. ARPE-19 cells were pre-treated with different doses (0.0, $0.1,0.5$ and $1.0 \mu \mathrm{M}$ ) of atRA for $1 \mathrm{~h}$, cells were then washed in PBS 3 times before being treated with $20 \mathrm{~mJ} / \mathrm{cm}^{2}$ of UV (A and B) or $\mathrm{H}_{2} \mathrm{O}_{2}(\mathrm{C}$ and D) and then incubated for $24 \mathrm{~h}$ in basic DMEM medium (without atRA), AQP1 expression was detected by Western blot analysis. Cells with or without $1 \mathrm{~h}$ of atRA (1.0 $\mu \mathrm{M})$ pretreatment were treated with $\mathrm{UV}$ or $\mathrm{H}_{2} \mathrm{O}_{2}$, and then incubated for 30 and $60 \mathrm{~min}$, and ERK phosphorylation was detected by Western blot analysis (E). Cells were treated with indicated doses of atRA for $24 \mathrm{~h}(\mathrm{~F}$ and $\mathrm{G})$, or treated with $1.0 \mu \mathrm{M}$ of atRA for indicated time points (H and $\mathrm{I})$. AQP1 expression was detected by Western blotting.

retinal pigment epithelial ARPE-19 cell line. Mechanistic studies showed that ROS-mediated ERK activation was involved in this process (Fig. 2). Notably, we observed that all-trans retinoic acid, which alone induced AQP1 upregulation, attenuated UV- and $\mathrm{H}_{2} \mathrm{O}_{2}$-induced AQP1 downregulation and water permeability impairment (Figs. 3 and 4).

Water movement across the plasma membrane can occur via two pathways: by diffusion through the lipid bilayer (26) and via membrane-inserted water channels (aquaporins) (27-29). AQP1 is so far the only known aquaporin expressed in RPE. It has been demonstrated that AQP1 is functionally expressed in RPE, and AQP1 facilitates water movement across RPE monolayers in an expression-dependent manner in these two complementary model systems, and the expression of AQP1 by RPE in vivo probably contributes to the efficient trans-epithelial water transport across RPE, maintains retinal attachment, and prevents subretinal edema (13). Our study demonstrated that UV and oxidative stress actually downregulated AQP1 expression and decreased water permeability which might be another mechanism to explain the impaired
RPE function after UV or oxidative stress $(1,30,31)$, since water permeability is involved in multiple important functions in RPE cells such as cellular junction formation, fluid or protein exchange and barrier formation $(13,15-17)$.

Our study also demonstrated that pre-treatment with alltrans retinoic acid attenuated UV- and oxidative stressinduced AQP1 downregulation and water permeability impairment (Figs. 3 and 4). This observation is consistent with our previous study (19) and other reports (32) showing that atRA has similar effects on AQP3. Our data further suggest that inhibition of ERK activation is involved in the effects of atRA against UV- or oxidative stress-induced AQP1 downregulation, which is also consistent with previous research using cultured skin keratinocytes (33). However, this does not exclude the possibility that mechanisms besides ERK inhibition might also be involved in the effect of atRA.

In conclusion, our study elucidated the mechanism through which UV and oxidative stress induce eye cell damage, namely the antioxidant-sensitive MEK/ERK pathway leading to downregulation of AQP1 and impairment 
A.

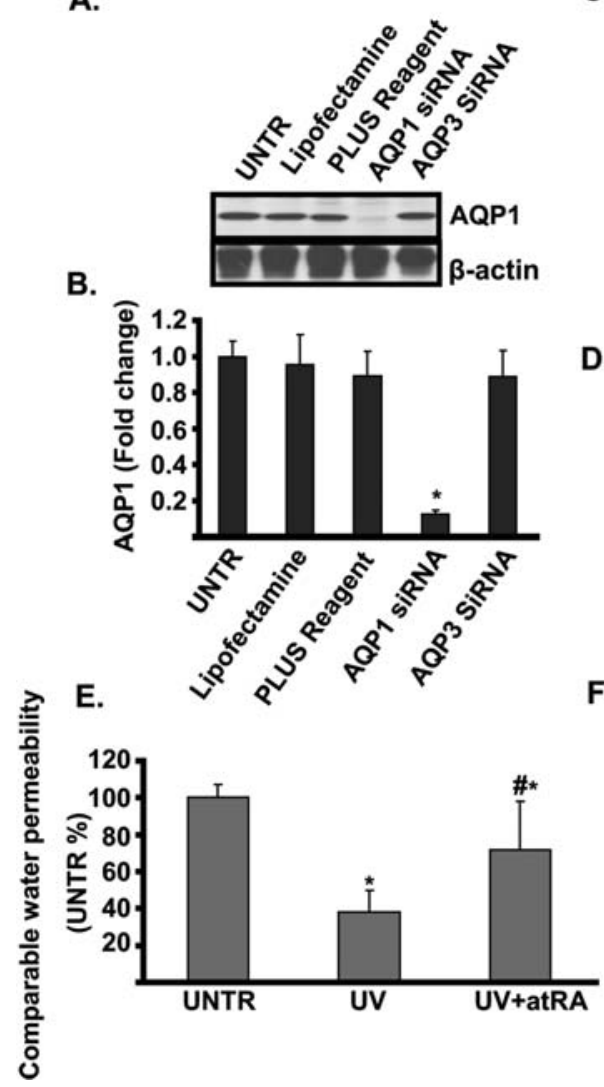

C. $?$

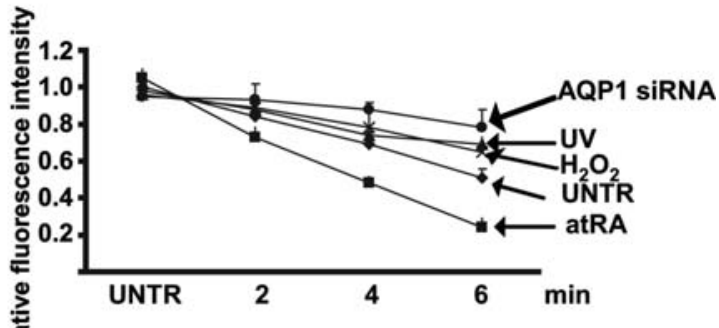

.

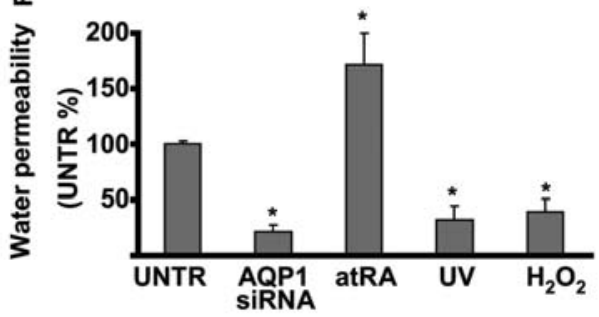

F.

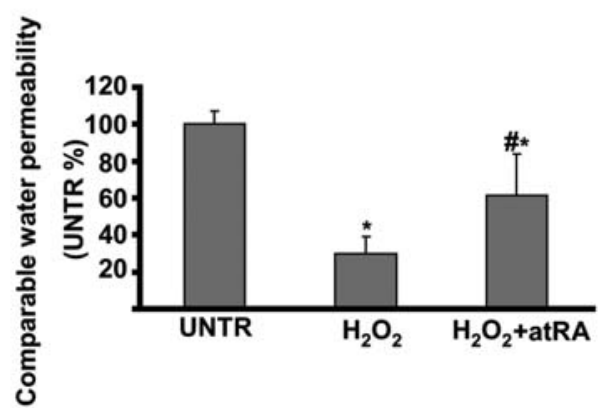

Figure 4. All-trans retinoic acid attenuates UV- and $\mathrm{H}_{2} \mathrm{O}_{2}$-induced impairment of water permeability in cultured human retinal pigment epithelial cells. ARPE19 cells were treated with AQP1 siRNA, control siRNA (AQP3 siRNA) or transfection control for $48 \mathrm{~h}$. AQP1 expression was detected by Western blot analysis (A and B). The water permeability of ARPE-19 cells with indicated treatments [untreated (UNTR), AQP1 siRNA for $48 \mathrm{~h}, 20 \mathrm{~mJ} / \mathrm{cm}^{2}$ of UV or $250 \mu \mathrm{M}$ of $\mathrm{H}_{2} \mathrm{O}_{2}$ for $24 \mathrm{~h}, 1 \mu \mathrm{M}$ of atRA for $24 \mathrm{~h}$ ] was analyzed by the methods described previously, and the relative intensity of calcein fluorescence in cytoplasmic regions of individual cells after transfections or treatment was quantified in (C). The half-life of deduction of fluorescence intensity was used as a comparable indicator of water permeability (D). ARPE-19 cells without or with atRA $(1 \mu \mathrm{M})$ pre-treatment were treated with UV $\left(20 \mathrm{~mJ} / \mathrm{cm}^{2}\right)$ or $\mathrm{H}_{2} \mathrm{O}_{2}$, and comparable water permeability was detected by the methods mentioned previously (E and F). For the cell water permeability experiments, at least 100 cells in 6 random views were quantified for relative fluorescence intensity. ${ }^{\mathrm{P}}<0.05$ vs UNTR; " $\mathrm{P}<0.05$ vs UV-treated group.

of water permeability in ARPE-19 cells. Our data support the notion that all-trans retinoid acid and antioxidants might be useful for protection against UV- and oxidative stress-induced eye cell damage.

\section{Acknowledgements}

This research was supported, in part, by a grant from the Natural Science Foundation of Jiangsu Province, China (BK2007234, Q.J.), a grant from the Natural Science Foundation of Jiangsu Higher Education Institutions of China (07KJD320140, Q.J.), a grant from the Nanjing Foundation for Development of Science and Technology, China (200801093, Q.J.) and by a grant from NIH (P20 RR016457 from INBRE Program of the National Center for Research Resources, Y.W.).

\section{References}

1. Roduit R and Schorderet DF: MAP kinase pathways in UVinduced apoptosis of retinal pigment epithelium ARPE19 cells. Apoptosis 13: 343-353, 2008.

2. Fujii N, Uchida $H$ and Saito T: The damaging effect of UV-C irradiation on lens alpha-crystallin. Mol Vis 10: 814-820, 2004.
3. De Oliveira Miguel NC, Meyer-Rochow VB and Allodi S: A structural study of the retinal photoreceptor, plexiform and ganglion cell layers following exposure to UV-B and UV-C radiation in the albino rat. Micron 34: 395-404, 2003.

4. Hiscott P, Sheridan C, Magee RM and Grierson I: Matrix and the retinal pigment epithelium in proliferative retinal disease. Prog Retin Eye Res 18: 167-190, 1999.

5. Kirchhof B and Sorgente N: Pathogenesis of proliferative vitreoretinopathy. Modulation of retinal pigment epithelial cell functions by vitreous and macrophages. Dev Ophthalmol 16: 1-53, 1989.

6. Liang FQ and Godley BF: Oxidative stress-induced mitochondrial DNA damage in human retinal pigment epithelial cells: a possible mechanism for RPE aging and age-related macular degeneration. Exp Eye Res 76: 397-403, 2003.

7. Patton WP, Chakravarthy U, Davies RJ and Archer DB: Comet assay of UV-induced DNA damage in retinal pigment epithelial cells. Invest Ophthalmol Vis Sci 40: 3268-3275, 1999.

8. Higgins GT, Wang JH, Dockery P, Cleary PE and Redmond HP: Induction of angiogenic cytokine expression in cultured RPE by ingestion of oxidized photoreceptor outer segments. Invest Ophthalmol Vis Sci 44: 1775-1782, 2003.

9. Dunn KC, Aotaki-Keen AE, Putkey FR and Hjelmeland LM: ARPE-19, a human retinal pigment epithelial cell line with differentiated properties. Exp Eye Res 62: 155-169, 1996.

10. King LS, Kozono D and Agre P: From structure to disease: the evolving tale of aquaporin biology. Nat Rev Mol Cell Biol 5: 687-698, 2004.

11. Verkman AS: More than just water channels: unexpected cellular roles of aquaporins. J Cell Sci 118: 3225-3232, 2005. 
12. Ruiz A and Bok D: Characterization of the 3' UTR sequence encoded by the AQP-1 gene in human retinal pigment epithelium. Biochim Biophys Acta 1282: 174-178, 1996.

13. Stamer WD, Bok D, Hu J, Jaffe GJ and McKay BS: Aquaporin-1 channels in human retinal pigment epithelium: role in transepithelial water movement. Invest Ophthalmol Vis Sci 44: 2803-2808, 2003.

14. Hara-Chikuma M and Verkman AS: Aquaporin-1 facilitates epithelial cell migration in kidney proximal tubule. J Am Soc Nephrol 17: 39-45, 2006.

15. La Cour $\mathrm{M}$ and Zeuthen $\mathrm{T}$ : Osmotic properties of the frog retinal pigment epithelium. Exp Eye Res 56: 521-530, 1993

16. Orgul S, Reuter U and Kain HL: Osmotic stress in an in vitro model of the outer blood-retinal barrier. Ger J Ophthalmol 2: 436-443, 1993

17. Adorante JS: Regulatory volume decrease in frog retinal pigment epithelium. Am J Physiol 268: C89-C100, 1995.

18. Jiang Q, Cao C, Zhou C, et al: Quercetin attenuates UV- and $\mathrm{H}(2) \mathrm{O}(2)$-induced decrease of collagen type I in cultured human lens epithelial cells. J Ocul Pharmacol Ther 24: 164-174, 2008.

19. Cao C, Wan S, Jiang Q, et al: All-trans retinoic acid attenuates ultraviolet radiation-induced down-regulation of aquaporin-3 and water permeability in human keratinocytes. J Cell Physiol 215: 506-516, 2008.

20. Cao C, Healey S, Amaral A, et al: ATP-sensitive potassium channel: a novel target for protection against UV-induced human skin cell damage. J Cell Physiol 212: 252-263, 2007.

21. Jiang Q, Zhou $\mathrm{C}$, Healey $\mathrm{S}$, et al: UV radiation down-regulates Dsg-2 via Rac/NADPH oxidase-mediated generation of ROS in human lens epithelial cells. Int J Mol Med 18: 381-387, 2006.

22. Fernandes AF, Zhou J, Zhang X, et al: Oxidative inactivation of the proteasome in retinal pigment epithelial cells: a potential link between oxidative stress and up-regulation of interleukin-8. J Biol Chem 283: 20745-20753, 2008.

23. Cao C, Sun Y, Healey S, et al: EGFR-mediated expression of aquaporin-3 is involved in human skin fibroblast migration. Biochem J 400: 225-234, 2006.
24. Cao C, Lu S, Sowa A, et al: Priming with EGFR tyrosine kinase inhibitor and EGF sensitizes ovarian cancer cells to respond to chemotherapeutical drugs. Cancer Lett 266: 249-262, 2008.

25. Bickers DR and Athar M: Oxidative stress in the pathogenesis of skin disease. J Invest Dermatol 126: 2565-2575, 2006.

26. Zelenina $\mathrm{M}$ and Brismar $\mathrm{H}$ : Osmotic water permeability measurements using confocal laser scanning microscopy. Eur Biophys J 29: 165-171, 2000.

27. Hara-Chikuma M and Verkman AS: Aquaporin-3 functions as a glycerol transporter in mammalian skin. Biol Cell 97: 479-486, 2005 .

28. Nakakoshi M, Morishita Y, Usui K, Ohtsuki M and Ishibashi K: Identification of a keratinocarcinoma cell line expressing AQP3. Biol Cell 98: 95-100, 2006.

29. Sasaki S, Ishibashi K and Marumo F: Aquaporin-2 and -3: representatives of two subgroups of the aquaporin family colocalized in the kidney collecting duct. Annu Rev Physiol 60 199-220, 1998.

30. Youn HY, Bantseev V, Bols NC, Cullen AP and Sivak JG: In vitro assays for evaluating the ultraviolet B-induced damage in cultured human retinal pigment epithelial cells. J Photochem Photobiol B 88: 21-28, 2007.

31. Biesemeier A, Kokkinou D, Julien S, et al: UV-A induced oxidative stress is more prominent in naturally pigmented aged human RPE cells compared to non-pigmented human RPE cells independent of zinc treatment. J Photochem Photobiol B 90: 113-120, 2008.

32. Bellemere G, Von Stetten O and Oddos T: Retinoic acid increases aquaporin 3 expression in normal human skin. J Invest Dermatol 128: 542-548, 2008.

33. Thiagarajah JR, Kim JK, Magzoub M and Verkman AS: Slowed diffusion in tumors revealed by microfiberoptic epifluorescence photobleaching. Nat Methods 3: 275-280, 2006. 